\title{
Evaluating the reliability of gestalt quality ratings of medical education podcasts: A METRIQ study
}

\author{
Jason M. Woods · Teresa M. Chan · Damian Roland · Jeff Riddell · Andrew Tagg · Brent Thoma (D)
}

Published online: 3 June 2020

(c) The Author(s) 2020

\begin{abstract}
Introduction Podcasts are increasingly being used for medical education. Studies have found that the assessment of the quality of online resources can be challenging. We sought to determine the reliability of gestalt quality assessment of education podcasts in emergency medicine.

Methods An international, interprofessional sample of raters was recruited through social media, direct contact, and the extended personal network of the study team. Each participant listened to eight podcasts (selected to include a variety of accents, number
\end{abstract}

Electronic supplementary material The online version of this article (https://doi.org/10.1007/s40037-020-00589-x) contains supplementary material, which is available to authorized users.

\section{J. M. Woods}

Section of Emergency Medicine, Children's Hospital Colorado, University of Colorado School of Medicine, Aurora, Colorado, USA

\section{T. M. Chan}

Division of Emergency Medicine, Department of Medicine, McMaster University, Hamilton, ON, Canada

\section{Roland}

Paediatric Emergency Medicine, Leicester Royal Infirmary, University of Leicester, Leicester, UK

\section{J. Riddell}

Department of Clinical Emergency Medicine, Keck School of Medicine, University of Southern California, Los Angeles, USA

\section{A. Tagg}

University of Melbourne, Melbourne, Australia

Footscray Hospital, Melbourne, Australia

\section{B. Thoma (凶)}

Department of Emergency Medicine, University of Saskatchewan, Saskatoon, Saskatchewan, Canada brent.thoma@usask.ca of speakers, and topics) and rated the quality of that podcast on a seven-point Likert scale. Phi coefficients were calculated within each group and overall. Decision studies were conducted using a phi of 0.8 .

Results A total of 240 collaborators completed all eight surveys and were included in the analysis. Attendings, medical students, and physician assistants had the lowest individual-level variance and thus the lowest number of required raters to reliably evaluate quality (phi $>0.80$ ). Overall, 20 raters were required to reliably evaluate the quality of emergency medicine podcasts. Discussion Gestalt ratings of quality from approximately 20 health professionals are required to reliably assess the quality of a podcast. This finding should inform future work focused on developing and validating tools to support the evaluation of quality in these resources.

Keywords Podcast · Gestalt · Reliability · FOAMEd

\section{Introduction}

Open educational resources such as blogs and podcasts are increasingly prevalent in emergency medicine [1]. A drastic increase in their availability [1] and use [2] has coincided with the rise of concerns regarding their quality [3, 4]. Podcasts are commonly utilized by emergency medicine residents in the United States [5], Canada [2], the United Kingdom, and Australia [6] and have been shown to affect clinical decision making in some settings [5]. Despite their potential impact on patient care, we are unaware of any studies which formally investigate their quality.

Studies have found the assessment of the quality of online resources to be difficult [7-11]. Resources have been developed to assist trainees and clinicians to assess the quality of blog posts [7, 12-14] but podcast listeners have had to rely upon their own gestalt to 
evaluate the quality of these resources. As the reliability of gestalt is limited by each individual's unique experience and learning needs $[15,16]$, the effectiveness of this approach is unclear.

We hypothesized that, like the gestalt evaluation of blog post quality $[8,12]$, clinicians will have broadly discrepant perspectives on the quality of individual podcasts. To test this hypothesis, we recruited an international, multidisciplinary sample of emergency clinicians to rate the quality of podcasts. If we are correct, our findings would provide empirical evidence to support concerns regarding users' ability to distinguish between high- and low-quality podcasts and suggest the need to develop of podcast-specific evaluation tools.

\section{Methods}

This study was deemed exempt from ethical review (Research Ethics Board, University of Saskatchewan, BEH 17-170). This work was carried out in accordance with the Declaration of Helsinki (http://www. wma.net/en/30publications/10policies/b3), including, but not limited to, there being no potential harm to participants, the anonymity of participants was guaranteed with regards to the results, and informed consent of participants was obtained.

\section{Participant recruitment and retention}

We recruited participants using the METRIQ study method [17] as described in greater detail elsewhere [18]. As the goal of this study was to obtain a representative sample of the virtual community of practice that concerns itself with medical education podcasts, we intentionally utilized an open process for participant recruitment. Communities of practice are made up of people who "share a common interest in a topic, and who deepen their knowledge and expertise by interacting on an ongoing basis" [19]. Dubé et al. further delineated the term virtual communities of practice to indicate the same shared features but where the primary interaction is in a virtual environment [20]. Our international authorship team promoted study participation by reaching out to their personal networks via email and their online community of practice via Facebook, Twitter, and WhatsApp. We also sent collaborators from the METRIQ blog study a recruitment email. Investigators from Canada, the United States, the United Kingdom, Australia, and South Africa conducted the study which aimed to recruit an international study population. We did not specify any particular level of expertise in either podcast listening or evaluation of medical education materials. We did this intentionally to recruit a sample representative of the general medical education podcasts listenership, rather than to recruit a cohort of content experts.

We directed potential participants to https:// METRIQstudy.org where they completed an intake form. Potential participants received a link to an initial survey within $24 \mathrm{~h}$ of completing the intake form. After it was completed [18], participants were directed to a series of eight podcasts and asked to respond to a brief survey after listening to each. We sent participants up to four reminders to complete each survey that were spaced out by 1-2 weeks. Participants who completed all surveys were included in the analyses and recognized as contributors to the METRIQ podcast study.

\section{Survey design and podcast selection}

The eight podcasts we selected for this study were sampled from websites tracked by the Social Medial Index [21, 22]. We chose this number of podcasts because we felt that this was the most that would be feasible for volunteer participants to complete as part of the study. The podcasts were intentionally selected to include a variety of accents (two each recorded by native speakers from Canada, the United States, the United Kingdom, and Australia) and number of speakers (four had a single speaker and four had multiple speakers). All podcasts were approximately $20 \mathrm{~min}$ in length (range 17 to $23 \mathrm{~min}$, mean $21.6 \mathrm{~min}$ ). To reduce the likelihood that participants had already listened to the podcast, we preferentially selected recently published podcasts. We organized the podcasts on a single podcast channel that could be accessed online or added to whatever podcast application was regularly used by the participants. This allowed participants to access the podcasts included in the study in the listeners' usual fashion. We received consent for the use of their content from the owner of each of the podcasts.

After listening to each podcast, participants responded to the question: Please indicate the extent to which you agree or disagree with the following statement: "This podcast episode was of high quality for medical education" with responses on a Likert scale from 1 (strongly disagree) to 7 (strongly agree). This question was modified from other studies evaluating the gestalt quality of open educational resources [13, $14,23,24]$ to be specific to podcasts.

\section{Data analysis}

We exported raw survey data from FluidSurveys and calculated descriptive statistics using Microsoft Excel. Calculations were conducted on both the full rater population and within all subgroups consisting of more than two raters. Generalizability studies (Gstudies), analysis of variance (ANOVA), and decision studies (D-studies) were conducted using G-String IV (Hamilton, ON, Canada). The D-studies determined the number of raters needed to achieve a phi of $\geq 0.80$ [25]. 
Table 1 Summary data for podcast raters

\begin{tabular}{|c|c|c|c|}
\hline Subgroups & $n$ & Age, mean (SD) & Gender \\
\hline \multirow[t]{3}{*}{ All participants } & \multirow[t]{3}{*}{240} & \multirow[t]{3}{*}{$33.1(7.9)$} & $56.0 \%$ male \\
\hline & & & $43.6 \%$ female \\
\hline & & & $0.4 \%$ prefer not to disclose \\
\hline \multirow{2}{*}{$\begin{array}{l}\text { Attending or consultant } \\
\text { physicians }\end{array}$} & \multirow[t]{2}{*}{73} & \multirow[t]{2}{*}{$38.0(7.0)$} & $69.9 \%$ male \\
\hline & & & $30.1 \%$ female \\
\hline \multirow[t]{2}{*}{ Pre-hospital care providers } & \multirow[t]{2}{*}{27} & \multirow[t]{2}{*}{$31.9(7.0)$} & $70.4 \%$ male \\
\hline & & & $29.6 \%$ female \\
\hline \multirow[t]{2}{*}{ Medical students } & \multirow[t]{2}{*}{67} & \multirow[t]{2}{*}{$26.6(3.8)$} & $49.3 \%$ male \\
\hline & & & $50.7 \%$ female \\
\hline \multirow[t]{3}{*}{ Nurse \& nurse practitioners } & \multirow[t]{3}{*}{22} & \multirow[t]{3}{*}{$39.3(9.6)$} & $27.3 \%$ male \\
\hline & & & $68.2 \%$ female \\
\hline & & & $4.5 \%$ prefer not to disclose \\
\hline \multirow[t]{2}{*}{ Physician assistants } & \multirow[t]{2}{*}{11} & \multirow[t]{2}{*}{$39.1(7.7)$} & $72.7 \%$ male \\
\hline & & & $27.3 \%$ female \\
\hline \multirow[t]{2}{*}{ Residents/Registrars/Fellows } & \multirow[t]{2}{*}{40} & \multirow[t]{2}{*}{$30.8(3.4)$} & $42.5 \%$ male \\
\hline & & & $57.5 \%$ female \\
\hline \multirow[t]{7}{*}{ Location } & \multirow[t]{7}{*}{240} & \multicolumn{2}{|l|}{ Canada $122(50.6 \%)$} \\
\hline & & \multicolumn{2}{|l|}{ United States $59(24.5 \%)$} \\
\hline & & \multicolumn{2}{|l|}{ Europe $32(13.3 \%)$} \\
\hline & & \multicolumn{2}{|l|}{ Oceana 14 (5.8\%) } \\
\hline & & \multicolumn{2}{|l|}{ Africa 9 (3.7\%) } \\
\hline & & \multicolumn{2}{|l|}{ South America 4 (1.7\%) } \\
\hline & & \multicolumn{2}{|l|}{ Asia $1(0.4 \%)$} \\
\hline
\end{tabular}

Table 2 Variance, generalizability, and decision studies

\begin{tabular}{|c|c|c|c|c|c|c|}
\hline & & ANOVA study & & & $\begin{array}{l}\text { Generalizability } \\
\text { study }\end{array}$ & Decision study \\
\hline & $\begin{array}{l}\text { Number of } \\
\text { raters in } \\
\text { group }\end{array}$ & $\begin{array}{l}\% \text { Variance } \\
\text { due to pod- } \\
\text { cast }\end{array}$ & $\begin{array}{l}\% \text { Variance due } \\
\text { to rater in group }\end{array}$ & $\begin{array}{l}\% \text { Variance due to Podcast } \\
\text { by rater }(p \times r) \text { interaction }\end{array}$ & $\begin{array}{l}\text { G-coefficient (Phi) } \\
\text { for the whole group }\end{array}$ & $\begin{array}{l}\text { How many raters in this group } \\
\text { needed to have a Phi coefficient } \\
\geq 0.80\end{array}$ \\
\hline All raters & 240 & $17.0 \%$ & $9.9 \%$ & $73.2 \%$ & 0.98 & 20 \\
\hline Attendings & 73 & $17.8 \%$ & $8.6 \%$ & $73.7 \%$ & 0.94 & 18 \\
\hline $\begin{array}{l}\text { Residents, regis- } \\
\text { trars, \& fellows }\end{array}$ & 27 & $15.0 \%$ & $9.4 \%$ & $75.6 \%$ & 0.88 & 23 \\
\hline Medical students & 67 & $21.6 \%$ & $8.7 \%$ & $69.7 \%$ & 0.95 & 15 \\
\hline $\begin{array}{l}\text { Nurses \& nurse } \\
\text { practitioners }\end{array}$ & 22 & $9.9 \%$ & $31.8 \%$ & $58.3 \%$ & 0.77 & 27 \\
\hline $\begin{array}{l}\text { Physician assis- } \\
\text { tants }\end{array}$ & 11 & $23.3 \%$ & $16.4 \%$ & $60.3 \%$ & 0.81 & 13 \\
\hline $\begin{array}{l}\text { Prehospital care } \\
\text { providers }\end{array}$ & 40 & $10.8 \%$ & $12.8 \%$ & $76.3 \%$ & 0.77 & 33 \\
\hline
\end{tabular}

\section{Results}

A total of 240 collaborators were included in the analysis. The study population included physicians and physician-trainees (residents/medical students), nurses, prehospital providers, and physician assistants. As only a single emergency medicine pharmacist participated so their data were excluded from the analysis. Tab. 1 depicts the subgroups of raters.

There was variation in the average quality ratings for the podcasts with the lowest rated 4.5 and the highest 6.2 on the 7-point Likert scale. The ANOVA, generalizability study, and decision study are shown in Tab. 2. The ANOVA found that prehospital providers and the nursing group had the greatest individuallevel variance. As the G-study phi co-efficient computes a measure of reliability of all raters in each group, it is affected by the number of raters (more raters, higher phi), the D-study calculation (how many raters needed from that group for a phi $\geq 0.80$ ) is a better comparison between the groups. The D-study found that physician assistants (13), medical students (15), and attendings (18) required the lowest numbers of raters to achieve adequate reliability while nurse/nurse practitioners had the highest (33). 


\section{Discussion}

This study evaluated the overall and subgroup-specific reliability of gestalt ratings of medical education podcast quality. Our results suggest that, with enough raters, gestalt can be used to determine the quality of educational podcasts. However, the ratings of small numbers of raters are insufficiently reliable. Further, our findings emphasize the need to develop tools that support podcast quality evaluation, which could build on the advances in quality evaluation of other open educational resources [12-14, 24].

Some subgroups were more reliable than others. The difference in magnitude of the D-studies for each group may relate to different interpretations of quality within each group that could stem from higher heterogeneity in these populations (e.g. resident/ registrar/fellow, nurse/nurse practitioner, and prehospital provider populations, may have more varied training experience than the other groups). Intuitively this makes sense, since a first-year postgraduate trainee (PGY1) will be unlikely to have the same perspective as a PGY5 or Fellow, who are much closer to the culmination of their training; whereas third- and fourth-year medical students may have very similar educational needs. Similarly, the nurse (consisting of both nurses and nurse practitioners) and prehospital (consisting of primary and advanced or critical care paramedics) clinician populations would arguably have greater diversity in training background than the physician assistant population which achieved the highest level of reliability. Other studies have only been conducted in physicians and physician trainees but have not consistently replicated this finding. $\mathrm{Kr}-$ ishnan et al. [11] found that trainees were less reliable than attendings when rating blog posts while Thoma et al. [7] did not find a substantial difference.

Our findings are substantively different from those evaluating other open educational resources such as blog posts. A previous D-study found that raters evaluating blog post quality using gestalt require at least 43 raters to achieve adequate reliability [7]. All of the subgroups in our study performed better than this when evaluating podcasts. While we can only speculate regarding why this was the case, it may be that podcasts are experienced more consistently than blog posts. It is also notable that this previous study was conducted in a more homogenous population (only medical students, emergency medicine residents, and emergency medicine attendings) so the opposite result (less reliability in this population) was more likely based upon the group composition alone.

The major strength of our study is its inclusion of a large and diverse sample of participants from multiple health professions that increases its generalizability. Further, this is the first study investigating the quality of online educational resources which included the perspectives of non-physician health practitioners. Our results demonstrate the variability in which clinicians evaluate podcasts and support the need for the development of evaluation tools that would guide the clinicians using them.

\section{Limitations}

As a survey-based study that utilized a social media recruitment strategy, this work has several limitations. The population that we targeted for recruitment were existing medical podcast listeners, so it is unlikely that these results would be generalizable to non-listeners and may be less relevant to podcast listeners who are not active on social media. As nearly $10 \%$ of the participants owned, operated, edited, or managed their own podcasts, our participants likely have more experience with podcasts than a general population of podcast listeners. The selected podcasts were delivered only in English and the participants were primarily from English-speaking countries, so the findings cannot be extended to other languages. Lastly, our pragmatic study design did not allow us to ensure that our participants listened to each podcast episode in full. While this behavior mirrors the real-world behavior of clinicians who listen primarily while exercising and commuting, it may affect their ability to reliably assess quality [26].

\section{Conclusions}

Gestalt ratings of quality from approximately 20 health professionals are required to reliably assess the quality of a podcast. This finding should inform future work focused on developing and validating tools to support the evaluation of these resources.

Acknowledgements The authors would like to acknowledge Annet Alenyo Ngabirano, Stevan Bruijns, Katie Knight, Scott Goerzen, and Timothy Horeczko for their assistance with participant recruitment and the METRIQ Podcast Study Collaborators for their contribution to the study.

Conflict of interest J.M. Woods, T.M. Chan, D. Roland, J. Riddell, A. Tagg and B. Thoma declare: Several of the authors currently or previously contributed to emergency medicine podcasts. None were compensated for their work. Otherwise the authors declare no conflicts of interest.

Open Access This article is licensed under a Creative Commons Attribution 4.0 International License, which permits use, sharing, adaptation, distribution and reproduction in any medium or format, as long as you give appropriate credit to the original author(s) and the source, provide a link to the Creative Commons licence, and indicate if changes were made. The images or other third party material in this article are included in the article's Creative Commons licence, unless indicated otherwise in a credit line to the material. If material is not included in the article's Creative Commons licence and your intended use is not permitted by statutory regulation or exceeds the permitted use, you will need to obtain permission directly from the copyright holder. To view a copy of this licence, visit http://creativecommons.org/licenses/by/4.0/. 


\section{References}

1. Cadogan M, Thoma B, Chan TM, Lin M. Free Open Access Meducation (FOAM): the rise of emergency medicine and critical care blogs and podcasts (2002-2013). Emerg Med J. 2014;31(e1):e76-e7.

2. Purdy E, Thoma B, Bednarczyk J, Migneault D, Sherbino J. The use of free online educational resources by Canadian emergency medicine residents and program directors. CJEM.2015;17:101-6.

3. Thoma B, Chan TM, Paterson QS, Milne WK, Sanders JL, Lin M. Emergency medicine and critical care blogs and podcasts: establishing an international consensus on quality. Ann Emerg Med. 2015;66:396-402.e4.

4. Lin M, Thoma B, Trueger NS, Ankel F, Sherbino J, Chan T. Quality indicators for blogs and podcasts used in medical education: modified Delphi consensus recommendations by an international cohort of health professions educators. Postgrad Med J.2015;91:546-50.

5. Riddell J, Swaminathan A, Lee M, Mohamed A, Rogers R, Rezaie SR. A survey of emergency medicine residents' use of educational podcasts. WestJ Emerg Med. 2017;18:229-34.

6. Thurtle N, Banks C, Cox M, Pain T, Furyk J. Free open access medical education resource knowledge and utilisation amongst emergency medicine trainees: a survey in four countries. Afr JEmerg Med. 2016;6:12-7.

7. Thoma B, Sebok-Syer SS, Krishnan K, et al. Individual gestalt is unreliable for the evaluation of quality in medical education blogs: a METRIQ study. Ann Emerg Med. 2017;70:394-401.

8. Rieh SY. Judgment of information quality and cognitive authority in the Web. JAm Soc InfSci Technol. 2002;53:145-61.

9. Rieh SY, Danielson DR. Credibility: A multidisciplinary framework. Annu RevInfSci Technol. 2007;41:307-64.

10. Metzger MJ. Making sense of credibility on the Web: Models for evaluating online information and recommendations for future research. J Am Soc Inf Sci Technol. 2007;58:2078-91.

11. Krishnan K, Thoma B, Trueger NS, Lin M, Chan TM. Gestalt assessment of online educational resources may not be sufficiently reliable and consistent. Perspect Med Educ. 2017;6:91-8.

12. Colmers-Gray IN, Krishnan K, Chan TM, et al. The revised METRIQ score: a quality evaluation tool for online educational resources. AEM Education and Training. 2019.

13. Chan TM, Thoma B, Krishnan K, et al. Derivation of two critical appraisal scores for trainees to evaluate online educational resources: a METRIQ study. West JEmerg Med. 2016;17:574-84.
14. Chan TM, Grock A, Paddock M, Kulasegaram K, Yarris LM, Lin M. Examining reliability and validity of an online score (ALiEM AIR) for rating free open access medical education resources. Ann Emerg Med. 2016;68:729-35.

15. RebJ,Cropanzano R. Evaluating dynamic performance: the influence of salient Gestalt characteristics on performance ratings. JAppl Psychol. 2007;92:490-9.

16. Ariely D, Carmon Z. Gestalt characteristics of experiences: the defining features of summarized events. J Behav Decis Making. 2000;13:191-201.

17. Thoma B, Paddock M, Purdy E, et al. Leveraging a virtual community of practice to participate in a survey-based study: a description of the METRIQ study methodology. AEM Educ Train. 2017;1:110-3.

18. Thoma B, Goerzen S, Horeczko T, et al. An international, interprofessional investigation of the self-reported podcast listening habits of emergency clinicians: A METRIQ Study. CJEM. 2020;22(1):112-117. https://doi.org/10.1017/cem. 2019.427.

19. Wenger EMR, Snyder WM. Cultivating communities of practice. Boston: Harvard Business School Press; 2002.

20. Dube L, Bourhis A, Jacob R. Towards a typology of virtual communities of practice. Interdiscip J Inf Knowl Manag. 2006;1:69-73.

21. Thoma B, Chan TM, Kapur P, et al. The social media index as an indicator of quality for emergency medicine blogs: a METRIQ study. Ann Emerg Med. 2018;72:696-702.

22. Thoma B, Sanders JL, Lin M, Paterson QS, Steeg J, Chan TM. Thesocialmediaindex: measuring theimpactofemergency medicine and critical care websites. West J Emerg Med. 2015;16:242-9.

23. Carpenter CR, Sarli CC, Fowler SA, et al. Best evidence in emergency medicine (BEEM) rater scores correlate with publications' future citations. Acad Emerg Med. 2013;20:1004-12.

24. Lin M, Joshi N, Grock A, et al. Approved instructional resources series: a national initiative to identify quality emergency medicine blog and podcast content for resident education. J Grad Med Educ. 2016;8:219-25.

25. Kamis O, Dogan CD. An investigation of reliability coefficients estimated for decision studies in generalizability theory. JEduc Learn. 2018;7(4):103.

26. Riddell J, Robins L, Brown A, Sherbino J, Lin M, Ilgen JS. Independent and interwoven: a qualitative exploration of residents' experiences with educational podcasts. Acad Med. 2020;95:89-96. 